\title{
Maxwell'in Alan Denklemleri Üzerine Bir Değerlendirme
}

\section{An Evaluation on Maxwell's Field Equations}

\author{
Semra Uçar ${ }^{1}$ (1)
}

'Dr. Öğr. Üyesi, Sinop Üniversitesi, Fen-Edebiyat Fakültesi, Sosyoloji Bölümü, Sinop, Türkiye

\section{ORCID: S.U. 0000-0002-9813-7640}

Sorumlu yazar/Corresponding author: Semra Uçar,

Sinop Üniversitesi, Fen-Edebiyat Fakültesi, Sosyoloji Bölümü, Sinop, Türkiye

E-mail/E-posta: semraucar@sinop.edu.tr

Başvuru/Submitted: 10.10.2019 Revizyon Talebi/Revision Requested: 11.12.2019

Son Revizyon/Last Revision Received: 18.12.2019

Kabul/Accepted: 18.12 .2019

\section{Atıf/Citation:}

Ucar, Semra. (2019). “Maxwell'in Alan Denklemleri Üzerine Bir Değerlendirme" Felsefe Arkivi-Archives of Philosophy, 51: 261270. https://doi.org/10.26650/arcp2019-5118

\section{ÖZET}

Maxwell, iki ayrı fenomen oldukları düşünülen elektrik ve manyetizmanın bir tek fenomenin iki ayrı bileşenleri olduğunu kendi alan denklemleri ile göstermiştir. Maxwell, sadece elektromanyetizmanın temel denklemlerini geliştirmekle kalmayıp aynı zamanda bu denklemleri, elektromanyetik dalgaların varlığını öngörmede ve ışığın bir elektromanyetik dalga olduğunu göstermede kullanmıştır. Bu çalışmada fizik tarihinden veriler kullanılarak, Maxwell'in alan denklemlerinin ortaya çıkısı ve etkileri araştırılmıştır. Değerlendirme sonucunda Maxwell'in evrenin işleyişini açıklama biçiminin devrimsel karakteri vurgulanmış ve buna rağmen yetersiz kaldığı noktalar tespit edilmiştir. Sonuç olarak evreni anlamada yeni açıklamaların kaçınılmaz olduğu ve bu açıklamalarda matematiğin oynadığı rol gösterilmeye çalışılmıştır.

Anahtar Kelimeler: Maxwell alan denklemleri, elektromanyetizma, fizik tarihi, fizik felsefesi, fizikte matematik

\section{ABSTRACT}

Maxwell has shown in his field equations that electricity and magnetism, which are thought to be two separate phenomena, are in fact two distinct components of a single phenomenon. Maxwell not only developed these fundamental equations but used them to predict the existence of electromagnetic waves and to show that light is an electromagnetic wave. In this study, I researched on the emergence and effects of Maxwell's field equations using data from the history of physics. As a result of the evaluation, I emphasized the revolutionary character of Maxwell's way of explaining the functioning of the universe and identified certain insufficient points. In conclusion, I tried to show that new explanations are inevitable in order to understand the universe and to show the role of mathematics in these explanations.

Keywords: Maxwell's field equations, electromagnetism, history of physics, philosophy of physics, mathematics in physics 


\section{Giriş}

1800’lü yılların sonlarına doğru, fizikte yeni ve devrimsel fikirler ortaya çıkmıştır. Bu görüşler klasik mekanik görüşten farklı olarak, yepyeni felsefi bakış açılarını doğurmuşlardır. Faraday ${ }^{1}$, Maxwell $^{2}$ ve Hertz' in ${ }^{3}$ elektrik ve manyetizma ile ilgili yaptıkları çalışmaların sonuçları modern fizikte büyük ilerlemeye öncülük etmiş ve gerçekliğin yeni bir tablosunu ortaya koymamıza yardımcı olacak kavramlar türetmişlerdir. ${ }^{4}$ Ortaya çıkan yeni kavramlar ve sonrasında yapılan çalışmalar, klasik fiziği adeta temelinden sarsmıştır. Özellikle termodinamik, elektrik ve manyetizma üzerine yapılan araştırmalar yirminci yüzyıl fiziğindeki araştırma ve düşünce yapısının temelini oluşturmuştur. Bu bakımdan bugünün temel sorunlarının, bilimin son iki yüz yıldaki gelişiminden doğduğunu söylemek mümkündür. ${ }^{5}$ Einstein'a göre Newton'dan bu yana kuramsal fiziğin temellerinde ilk köklü ve asıl büyük ilerlemeyi sağlayan Faraday ile Maxwell'in optik ve elektrodinamikteki devrimci ve altüst edici işlemleri bile tümüyle Newtoncu fikirlerin himayesi ve yönlendirmesi altında gerçekleşmiştir. ${ }^{6}$ Bunun anlamı ise mekanik bir dünya görüşünden yola çıkılıp elektromanyetizma kuramı içine optiğin katılması ve onunla bütünleştirilmesi, fiziğin temellerinin birleştirilmesine yönelik uğraşlardaki en büyük zaferlerden birini teşkil ve temsil etmesidir; Maxwell'in bu birleştirmeye katkısı salt kuramsal kanıtlamalardır. ${ }^{7}$ Onun bu kuramsal kanıtlamaları, Volta ${ }^{8}$, Ampère ${ }^{9}$, Ørsted ${ }^{10}$, Henry $^{11}$ ve diğerlerinin elektrik ve manyetizma ile ilgili yaptıkları öncü çalışmaları birleştirmeye yöneliktir. Bu çalışma, Maxwell’in söz konusu birleştirici kuramsal kanıtlamalarını ortaya koyduğu alan denklemlerini merkeze almaktadır. Bu nedenle ilk olarak Maxwell'in alan denklemlerinin ortaya çııış süreci, fizik tarihinden verilerle ortaya konmuştur. Bu veriler ikinci kısımda ele alınacak olan, denklemlerin matematiksel yapısını yorumlamada kullanılmıştır. Denklemlerin matematiksel yapısının yorumlanması, karşılık geldiği fizik gerçeklik ve denklemlerin bilim tarihindeki etkilerinin sorgulanmasına olanak vermiştir. Sonuç kısmında, Maxwell'in kavramsal düzeyde yapmış olduğu devrimin, modern fiziğin ortaya çıkış sürecindeki önemi ile değişen evren algısı ve evreni açıklama biçimlerinin felsefi bağlamı ortaya konmuştur. Bu tartışma, evrenin klasik mekanik açıklamasının yetersiz kalıp, yeni açıklamaların kaçınılmaz olduğunu ve matematiğin bu kaçınılmaz durumun neresinde olduğunu göstermiştir.

\footnotetext{
Michael Faraday (1791 Londra - 1876 Hampton Court), İngiliz Kimyacı ve Fizikçi.

James Clerk Maxwell (1831 Edinburgh - 1879 Cambridge), İskoç Matematikçi ve Fizikçi.

Heinrich Rudolf Hertz (1857 Hamburg - 1894 Bonn), Alman Fizikçi.

Albert Einstein, Leopold Infeld, Fiziğin Evrimi, çev. Sertaç Turgal (Ankara: Alter Yayıncılık, 2015), 125.

Werner Heisenberg, Çă̆daş Fizikte Doğa, çev. Vedat Günyol ve Orhan Duru (Ankara: V Yayınları, 1987), 33.

Albert Einstein, Bilim ve Felsefe Yazıları, çev. Nejat Bozkurt (Ankara: Sentez Yayıncılık, 2013), 130.

Einstein, Bilim ve Felsefe Yazular, 269.

Alessandro Volta (1745 Como - 1827 Camnago), İtalyan Fizikçi.

André Marie Ampère (1775 Lyon - 1836 Marsilya), Fransız Fizikçi ve Matematikçi.

10 Hans Christian Ørsted (1777 Rudkøbing - 1851 Kopenhag), Dan Fizikçi ve Kimyacı.

11 Joseph Henry (1797 Albany - 1878 Washington ), Amerikan Fizikçi.
} 


\section{Maxwell'in Alan Denklemleri}

\subsection{Denklemlerin Ortaya Çıkış Süreci ve Etkileri}

Bilim tarihinde 19. yüzyılın ilk yarısı özellikle elektrik, manyetizma ve ş̧ık konularındaki çalışmaların ön plana çıktığı bir dönemdir. Newton'un kütle çekimi kuramı, evreni mekanik bir maddeye indirgeyerek açıklamaktaydı. Bu açıklamaya göre, değişik büyüklükteki kütlesel nesnelerin, elektrik yükleri gibi birbirlerini etkilediği temel varsayım olarak kabul edilmekteydi. Faraday bu görüşü ilerleterek elektrik yüklerinin yalnızca birbirlerini değil, çevrelerini de etkilediği görüşüne ulaşmışıır. ${ }^{12}$ Yük yoğunluğunun zamanla değişiyor olması, yük korunumu ilkesi nedeniyle bir akımın da zorunlu olarak aynı anda var olması sonucunu doğurmaktadır. Bunun anlamı, zamanla değişen bir elektrik alanın yanı sıra zorunlu olarak, her zaman bir de manyetik alan yaratıldığıdır. Faraday, 1831 yılında yapmış olduğu deneylerle bunun tersinin de doğru olduğunu göstermiştir. Başka bir ifadeyle zamanla değişen bir manyetik alan, beraberinde bir de elektrik alanın yaratılmasına neden olmaktadır. ${ }^{13} \mathrm{O}$, 'elektromanyetik kuvvet alanı' olarak isimlendirdiği yeni bir kavram ortaya atmıştır. Ona göre bu alan da uzayda diğer fizik nesnelerden bağımsız kendine özgü bir gerçekliktir. Değişen manyetik alanın bir iletkende elektrik ürettiğini saptayan Faraday, bu olayı 'elektromanyetik indüksiyon' olarak nitelemiştir. ${ }^{14} \mathrm{Bu}$ özellikler zamanla değişim söz konusu olduğu hallerde elektrik ve manyetik alanların birbirinden ayrı düşünülmesinin olanaksız olduğu, gerçekte bunların bir tek olayın iki bileşeni durumunda olduklarını göstermektedir. Söz konusu olaylara 'elektromanyetik olaylar' denmektedir. Bunları inceleyen bilim dalı da 'elektromanyetizma' adını almışır. ${ }^{15} \mathrm{Bu}$ sürecin kuramsal yapısını belirleyen isim ise Maxwell'dir.

Maxwell, 1854 te Cambridge'de derecesini aldıktan sonra, Thomson'un ${ }^{16}$ elektromanyetizmanın mekanik açıklamaları ve ısının katı cisimlerden akma biçimi ile elektrik kuvvetlerin oluşturduğu örüntüler arasında bulduğu matematiksel analojiyi ve Faraday'ın elektrikle ilgili yapmış olduğu çalışmaları dikkatlice değerlendirmiştir. Ertesi yıl, Faraday'n elektromanyetik indüksiyon ile ilgili doktrinini, manyetik ve elektrik ortamın etrafını çevreleyen alanın tamamında bir durum değişikliği yarattığına yönelik olduğunu tespit etmiştir. ${ }^{17}$ Faraday, elektrik ve manyetik kuvvet çizgilerini gözlemlerine dayandırıyordu. Ancak Maxwell'in gözlemsel sonuçları, klasik mekanik ve elektromanyetik kuramın ilkeleri arasında bir çelişki olduğunu ortaya koymuştur. Fresnel' 'n $^{18}$ ışığın eter teorisinin başarılı oluşundan kısa bir süre sonra, Maxwell elektromanyetik alan teorisini geliştirmişstir. Bu teori, elektrik ve manyetik alanların, yükler ve akımlar tarafından nasıl değiştirildiği ve üretildiğini tanımlamaktadır. Buna ek olarak teori, elektromanyetik dalgaların varlığını öngörmüştür ve ışığın elektromanyetik dalga olduğunu göstermede kullanılmıştır. Buna göre ışık, elektromanyetik alanda, bir madde olarak değil, bir dalga olarak hareket etmektedir. Deneysel

12 John Gribbin, Bilim Tarihi, çev. Barış Gönülşen (İstanbul: Alfa Yayıncılık, 2013), 452-456.

13 Mithat İdemen, Elektromanyetik Alan Teorisinin Temelleri (İstanbul: İTÜ Vakfi Yayınları, 2015), 103.

14 Gribbin, Bilim Taribi, 452-456.

15 İdemen, Elektromanyetik Alan Teorisinin Temelleri, 103.

16 William Thomson (1824 Belfast- 1907 Largs), İskoçyalı Fizikçi.

17 Gribbin, Bilim Taribi, 461.

18 Augustin Jean Fresnel (1788 Broglie - 1827 Ville- d'Avray), Fransız Fizikçi. 
nedenler gibi eterin mekanik modelleri de Maxwell'in klasik elektromanyetizma kuramının temelini oluşturmasını sağlamıştır. ${ }^{19}$ Onun elektromanyetizmanın dinamik kuramı üzerine yaptığ 1 çalışmaları ilk kez 1864 tarihinde ${ }^{20}$, Alan denklemleri ise tam olarak ilk kez 1873'de "Treatise on Electricity and Magnetism" ${ }^{21}$ adlı çalışmasında yayımlanmıştır.

Elektrik ve manyetizma için Maxwell denklemleri, Isaac Newton'dan sonra bir ilk olarak görülerek fizikteki ikinci büyük birleşim olarak değerlendirilmektedir. Bir başka ifadeyle Maxwell'in elektromanyetik ışımanın klasik teorisini formüle etmesi, ilk kez elektrik, manyetizma ve ışı̆̆ bir araya getirerek aynı düzlemde ortaya koyması fizik tarihindeki en büyük başarılardan biri olarak yorumlanmaktadır. Çünkü Maxwell'in optik, elektrik ve manyetik kuramları, bir tek elektromanyetik alan kavramında birleştirerek hepsinin aynı temel yasaların değişik belirişleri olduğunu göstermesi, evren algımızda ve evreni anlamlandırma çabamızda büyük bir değişimin başladığını göstermiştir. Maxwell'in kuramsal olarak varsaydığı olaylar, ölümünden sonra Hertz' in düşük frekanslı radyo dalgaları ile Röntgen'in ${ }^{22}$ yüksek frekanslı X-ışınları bulgularıyla deneysel olarak doğrulanmıştır. ${ }^{23}$

Bu alan denklemleri, daha sonra Einstein'ın geliştirdiği özel görelilik kuramına temel oluşturmuş ve kuantum kuramının geliştirilmesinin yolunu açmıştır. Einstein, görelilik teorisi ile ilgili ilk çalışmasında sadece üç isimden bahsetmiştir. Bu isimler, Maxwell, Hertz ve Lorentz'dir. ${ }^{24} \mathrm{O}$, “özel görelilik kuramı, köklerini elektromanyetik alanın Maxwell denklemlerine borçludur” demiştir. ${ }^{25}$ Denklemlerin yarattığı bu etkileri değerlendirmede, onların matematiksel yapılarının ortaya çıkış süreci ve yorumlanışları faydalı olacaktır.

\title{
2. 2. Maxwell Denklemlerinin Matematiksel Yapısı Üzerine
}

Elektrik ve Manyetizma Üzerine adlı eserinde Maxwell, Faraday'ın deneyler yoluyla türettiği kavramsal yapıyı ve fiziksel düşüncelerini matematiksel bir yapıya dönüştürmüştü. ${ }^{26}$ Maxwell, bu matematiksel keşif sürecinin başlangıcını şöyle ifade etmiştir:

\begin{abstract}
“Elektrik üzerine çalışmaya başlamadan önce Faraday'ın Elektrik Üzerine Deneysel Araştırmalar ${ }^{27}$ adlı eserini ilk kez okuyana dek konuyla ilgili hiç matematik okumamaya karar vermiştim. Faraday'ın olayları düşünme şekliyle matematikçilerinki arasında bir fark olması gerektiğinin farkındaydım; çünkü ne o ne de diğerleri birbirlerinin kullandığg dilden tatmin olabiliyordu. $\mathrm{Bu}$ uyumsuzluğun iki taraftan herhangi birinin yanılması nedeniyle olmadığı kanısına
\end{abstract}

19 James Ladyman, Understanding Philosophy of Science (London and New York: Routledge, 2002), 245.

20 John David Jackson, Classical Electrodynamics (New York: John Wiley \& Sons, Inc., 1962), 1.

21 Bkz., James Clerk Maxwel, Treatise on Electricity and Magnetism (London: Macmilan and Co, 1873).

22 Wilhelm Röntgen (1845 Lennep - 1923 Münih), Alman Fizikçi.

23 James T. Cushing, Fizikte Felsefi Kavramlar, çeviren Özgür Sarığlu (İstanbul: Sabancı Üni. Yayınları, 2006), 27.

24 Abraham Pais, Subtle is the Lord (Hampshire: Oxford University Press, 2005), 121.

25 Cushing, Fizikte Felsefi Kavramlar, 28.

26 Michael Guillen, Dünyayı Değiştiren Beş Denklem, çev. Gürsel Tanrı̈ver (Ankara: Tübitak Yayınları, 2002), 164.

27 Bkz., Micheal Faraday, Experimental Researches in Electricity (London: R. and J. E. Taylor, 1839). 
da sahiptim. Buna ilk kez, konu hakkında öğrendiğim çoğu şey için yayınlanmış makalelerine olduğu kadar, verdiği öğütlere ve yardımlara da borçlu olduğum Sir William Thomson tarafından inandırıldım." ${ }^{28}$

Maxwell, fiziksel olguları yorumlama, matematiğin çarpıcı işlevi ve sürecin devamı konusunda şunları dile getirmiştir:

"Faraday’ı çalışmaya devam ederken, olayları düşünme yönteminin geleneksel matematiksel simgeler yoluyla açıç̧a sergilenmiş olsa da aslında matematiksel olduğunu kavradım. Aynı zamanda bu yöntemlerin olağan matematiksel biçimlerde ifade edilebileceklerini de buldum.

Örnek olarak Faraday, aklının gözüyle uzayın tümü içinden geçen kuvvet çizgileri görürken, matematikçiler belli bir uzaklıkta çeken kuvvet merkezleri görüyorlardı: Faraday bir ortam görürken onlar uzaklık dışında bir şey görmüyorlardı; Faraday olayların oturdukları yeri ortamda süre giden gerçek etkilerde arıyordu. Onlarsa bunu elektrik sıvıları üzerine etki ettirilen bir uzaklıktaki etkinin gücünde bulduklarını düşünerek hoşnuttular." ${ }^{29}$

Maxwell keşif sürecini nasıl tamamladığını ve bilimsel açıklama yöntemlerinin neredeyse birbirlerine zıt olmalarına rağmen nasıl işlediğini şöyle yorumlamıştır:

\begin{abstract}
"Faraday'ın fikirleri olduğunu düşündüklerimi matematiksel bir biçime çevirdiğimde, iki yöntemin sonuçlarının genellikle birbirleriyle aynı olduklarını buldum. Böylelikle hem aynı olayların nasıl oldukları açıklanmış hem de her iki yöntem tarafından da aynı etki yasaları ortaya çıkarılmış oluyordu; fakat Faraday’ın yöntemleri bütünden başlayıp çözümlemelerle parçalara ulaştıklarımıza benzerken, olağan matematiksel yöntemler parçalardan başlayıp sentez yoluyla bütünü oluşturma ilkesi üzerine kuruluydular.
\end{abstract}

Ayrıca matematikçiler tarafından keşfedilmiş en verimli araştırma yöntemlerinin bazılarının özgün biçimlerinde olmak yerine, Faraday tarafından elde edilen fikirler cinsinden çok daha iyi ifade edilebildiklerini de buldum." ${ }^{30}$

Maxwell'in büyük sentezi öncesinde, elektrik ve manyetizmanın ayrı alanlarının, temel yasaları sırasıyla sabit bir $q$ nokta yükünün oluşturduğu $E$ elektrik alanı için Coulomb yasası ve $i$ akımı taşıyan bir tel tarafından üretilen $B$ manyetik alanı için Biot-Savart yasasıydı. ${ }^{31}$ Klasik kütle çekimsel etkiler için Newton'un yasalarının var olması gibi, bir bakıma elektromanyetik olaylar için var

28 Maxwell, Elektrik ve Manyetizma Üzerine Ayrıntılı Bir İnceleme (NewYork: Dover Yayıncılık, 1954), viii-ix. Akt; James T. Cushing, Fizikte Felsefi Kavramlar, çev. Özgür Sarığlu (İstanbul: Sabancı Üni. Yayınları, 2006), 15-16.

29 Cushing, Fizikte Felsefi Kavramlar, 15-16.

30 Cushing, Fizikte Felsefi Kavramlar, 15-16.

31 Cushing, Fizikte Felsefi Kavramlar, 23. 
olan bu dinamik yasaların içeriği, hareketsiz duran ve hareket eden yüklerin ${ }^{32}$, sırasıyla elektrik ve manyetik alanları nasıl oluşturduklarını niceliksel ayrıntılarla betimlemeleridir. Maxwell'in Íncelemesi sonrasında aldıkları hal bakımından elektromanyetizma yasaları, bu elektrik ve manyetik alanların boş uzayda ${ }^{33}$, bir dalga denklemi sağlamalarını gerektirmiştir. Bu, elektrik ve manyetik alanların uzayda $c^{34 *}$ hızıyla yayılabilmeleri anlamına gelmektedir. Dolayısıyla yayılan $E$ ve $B$ alanları Maxwell denklemlerinin çözümleridir. Denklemler, bu $E$ ve $B$ alanlarının aynı zamanda birbirlerine dik olmalarını da gerektirirler. (Şekil 1) Bu alanların birbirlerine göre doğrultularını ve yayılma yönünü (c) gösterirken, (Şekil 2) bir sinüs eğrisi gibi yayılan alanlar dizisini göstermektedir: ${ }^{35}$

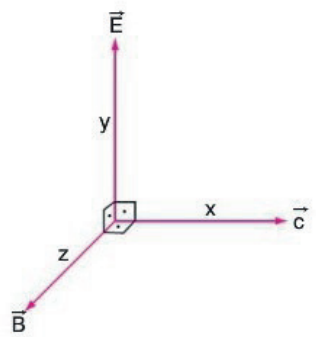

Şekil 1. Karşılıklı olarak birbirlerine ve c yayılma yönüne dik olan E ve B alanları

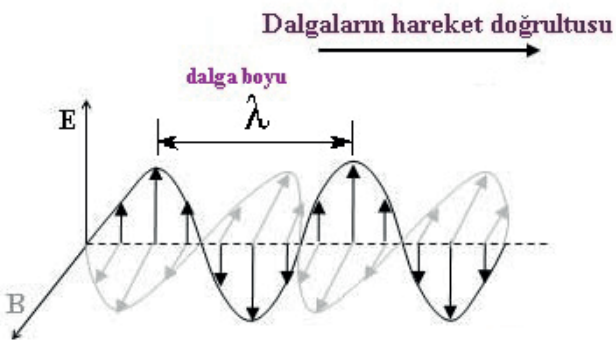

Şekil 2. Yayılmakta olan bir düzlem emd

Maxwell kuramının en önemli başarılarından biri, söz konusu elektromanyetik dalgalarının yayılma hızının sayısal olarak noktasal yükler arasındaki (elektrostatik) çekimi (ya da itmeyi) veren Coulomb yasasında rol oynayan $(k 1)$ orantı katsayısı ile ona karşılık olarak akım taşıyan iki tel arasında etki eden (manyetik) kuvveti belirleyen temel yasada ortaya çıkan ( $k 2$ ) orantı katsayısının oranının kareköküne eşit olmasını öngörmesidir. Temel nokta, bu sabitlerin her birinin birbirinden bağımsız, sırasıyla elektrostatik ve manyetik ölçümleri temel alan deneyler aracılığıyla sayısal olarak belirlenmiş olduğu ve Maxwell'in çalışması öncesinde $c$ şsık hızının da deneysel olarak ölçüldügüudür. Bu öngörülen hızın değerinin, sşığın boşluktaki hızına $(c)$ sayısal olarak eşit olduğu ortaya çıkar.

32 Birim zamanda hareket eden yük miktarına 'akım' denmektedir.

33 Boş uzay: İçinde herhangi bir yük ya da akım bulunmayan bir bölge.

$34{ }^{*}$ c: Işıı hızı. Boş uzayda büyüklüğü $3 \times 10^{8} \mathrm{~m} / \mathrm{s}^{\prime}$ dir.

35 Cushing, Fizikte Felsefi Kavramlar, 23-24. 
Bu tamamen bir rastlantı olabilecekken, bunu ışığın bir elektromanyetik dalga olduğunun belirtisi olarak ele almak çok daha akla yatkın görünmektedir. ${ }^{36}$

Maxwell'in denklemlerinde ortaya çıkan bu hız $(c)$, mutlak bir referans noktasının tanımlanabileceği umudunu sağllyor gibi görünüyordu; çünkü $c$ nin belirli bir sisteme göre ölçülen hız olması gerekirdi. Eter, ışık hızının ona göre ölçüldüğünde $\left(c=3 \times 10^{8} \mathrm{~m} / \mathrm{s}\right)$ sayısal değerini aldığı referans noktası olarak hizmet edecekti. Yani Newton'un ikinci hareket yasası ( $\mathrm{F}=\mathrm{ma})$ herhangi bir hızı değil, yalnızca ivmeyi içerirken; Maxwell denklemleri (bkz., Tablo 1) açıkça hızı barındırırlar. Bu nedenle Newton'un dinamiği tek ve benzersiz bir eylemsiz referans sistemini diğerinden ayırt edemezken, Maxwell'inki bunu yapabiliyor görünüyordu. ${ }^{37}$

Maxwell, manyetizma için $B$ ve elektrik için $E$ simgelerini kullanmıştır. Ayrıca bir şeyin artma ve azalma hızı için $-\frac{\partial}{\partial t}$ ve miktarı için de $\nabla \times$ simgelerine başvurmuştur. ${ }^{38} p$, serbest yük yoğunluğu; J ise akım yoğunluğuna karşılık gelmektedir. ${ }^{39} \mathrm{dA}=$ Alan elemanı, $\mathrm{dS}=$ Uzunluk elemanı'nı temsil etmektedir.

Maxwell denklemleri, Lorentz ${ }^{40}$ kuvvet yasaları ile birlikte klasik elektrodinamik, klasik optik ve elektrik devrelerine kaynak oluşturan ve elektromanyetik olayları açıklayan dört denklemden oluşmaktadır: Bu dört denklemin integral formları ve türev ifadeleri ile aşağıda Tablo 1'de verilmiştir:

\begin{tabular}{|c|c|c|}
\hline İntegral Formları & Türev ifadeleri & Açıklama \\
\hline$\oint_{(1 . \mathrm{a})} E \cdot d A=\frac{Q}{\varepsilon_{0}}$ & $\nabla . E=\frac{\rho}{\varepsilon_{0}}$ & (Coulomb Yasası) \\
\hline$\oint_{(1 . b)} B \cdot d A=0$ & $\nabla \cdot B=0$ & (Manyetik Yük Yoktur) \\
\hline$\oint_{(1 . c)} E \cdot d S=-\frac{d \Phi_{m}}{d t}$ & $\nabla \times E=-\frac{\partial B}{\partial t}$ & $\begin{array}{l}\text { (Faraday'in İndüksiyon } \\
\text { Yasası) }\end{array}$ \\
\hline$\oint_{(1 . \mathrm{d})} B \cdot d S=\mu_{0} I+\varepsilon_{0} \frac{d \Phi_{m}}{d t}$ & $\nabla \times B=\mu_{0}\left(J+\varepsilon_{0} \frac{\partial E}{\partial t}\right)$ & $\begin{array}{l}\text { (Maxwell'in Yer Değiştirme } \\
\text { Akımıly Ampère Yasası) }^{41}\end{array}$ \\
\hline
\end{tabular}

Tablo 1'deki (1.a) denklemi, elektrik için Gauss yasası olarak adlandırılır. Coulomb'un nokta yükler için ters kare yasasının genelleştirilmiş halidir ve alanların yüklerden nasıl oluştuğunu

36 Cushing, Fizikte Felsefi Kavramlar, 25.

37 Cushing, Fizikte Felsefi Kavramlar, 25.

38 Guillen, Dünyayı Değiştiren Beş Denklem, 164.

39 Tekin Dereli ve Abdullah Verçin, Kuantum Mekaniği (Ankara: Türkiye Bilimler Akademisi, 2014) 298.

40 Hendrik Lorentz (1853 Arnhem - 1928, Haarlem), Hollandalı Fizikçi.

41 Cushing, Fizikte Felsefi Kavramlar, 38. 
açıklamaktadır. (1.b) denklemi, manyetik nokta yükleri ve kaynakları olmadığını belirtir. Manyetik alan içinde manyetik yük diye bir şey yoktur. Bu nedenle manyetik alan çizgileri asla kesişmez veya sonlanamaz ve daima kapalı döngüler oluşturur. (1.c) denklemi, Faraday’ın manyetik indüksiyon yasasının bir ifadesidir. Yani manyetizma tarafından üretilen elektriğin miktarı, manyetik kuvvetin artma veya azalma hızına eşit olmaktadır. Çok hızlı bir şekilde değişen bir manyetik kuvvet çok miktarda elektrik, yavaşça değişen bir manyetik kuvvet ise çok küçük bir miktar elektrik üretmektedir. Zaman içinde sabit kalan bir manyetik kuvvet ise hiç elektrik üretmez. (1.d) denklemi ise alanların kendi kaynaklarının çevresinde nasıl dolaştığını açıklamaktadır. Manyetik alan elektrik akımları ve Maxwell düzeltmesi ile Ampère yasasına göre zamanla değişen manyetik alanlar çevresinde dolaştığını ifade etmektedir. ${ }^{42}$

Idemen'e göre Maxwell denklemleri olarak bilinen bu bağıntıların zamanla değişim yok iken elektrostatik ve manyetizmanın temel denklenmelerine indirgendiği açıcça görülmektedir. ${ }^{43} \mathrm{Bu}$ denklemlerin iki önemli özelliğinden biri yerel (lokal) olmalarıdır. Yani elektromanyetik alanın bileşenlerinin bir noktadaki ve bir andaki değerlerini birbirlerine bağlarlar. Diğer özelliği ise Maxwell denklemleri, içinde olayın geçtiği ortamdan bağımsız, evrensel ${ }^{44^{*}}$ denklemlerdir. $^{45}$

Newton'un kuramsal fiziği temellendirip kurmasından bu yana fiziğin hipotetik temelinde ve fizik gerçekliğin yapısını algılayışımızdaki en büyük değişim, Faraday ve Maxwell'in elektromanyetik fenomenler üzerindeki araştırmalarıyla meydana gelmiştir. ${ }^{46}$ Maxwell, elektromanyetik alan ve dalga kavramlarını geliştirerek fizik gerçeklik kavramındaki büyük değişimin ilk ve en önemli adımını atmıştır. Maxwell'den sonra fizik gerçeklik, kısmi diferansiyel denklemler ve sürekli alanlarla temsil edilen bir olgu olarak da tasarlanmaya başlamıştır. Fizik gerçeklik ile ilgili bu değişim bilim tarihinin en önemli dönüm noktalarından biri olarak kabul edilebilir. Elektrodinamikte, sürekli alan, kaynak olarak maddesel parçacıklarla yan yana olarak fizik gerçekliğin temsili olarak ortaya çıkmaktadır. Bu düalizmin, bugün ortadan kalktığını söylemek pek mümkün gözükmemektedir. Maxwell'in zamanından bu yana, fiziksel gerçekliğin, kısmi diferansiyel denklemlerin yönettiği sürekli alanlar tarafından temsil edildiği düşüncesine yönelik eleştiri, açılamaların mekanik yorum gücüne sahip olmadığı yönündeydi. $\mathrm{O}$ zamandan beri kurulmuş olan başarılı fiziksel sistemler, Newton ve Maxwell'inkiler arasında bir uzlaşmayı temsil etmektedir.

\section{Tartışma ve Sonuç}

Bilimsel bilgi üretmede amaç, doğayı, evreni tanımak ve onun işleyiş kurallarını anlamaya çalışmaktır. Çoğunlukla bu konuda bilim insanının dürtüsü, sadece meraktır. Ancak bilim insanı, bu çabasının sonucu olarak ortaya çıkabilecek olan yararın ya da kullanımın ne olabileceğini çoğu zaman kestiremez. Maxwell de bu bilim insanlarından biridir.

42 John R. Reitz ve Frederick J. Milford, Foundations of Electromagnetic Theory (London: Addison-Wesley Publishing Company, Inc, 1992), 294-295.

43 İdemen, Elektromanyetik Alan Teorisinin Temelleri, 103.

$4{ }^{*}$ Bu türden denklemlere 'alan denklemleri' adı verilmektedir.

45 İdemen, Elektromanyetik Alan Teorisinin Temelleri, 103-104.

46 Einstein, Bilim ve Felsefe Yazılar, 143. 
Elektromanyetizma konusunda Maxwell odaklı olarak ele aldığımız bu gelişmeler dizisi, modern bilimin birçok alanında tipik olarak görülen örneklerden biridir. Önce temel olgular deneysel olarak gözlemlenmiştir. Daha sonra bunları yöneten yasalar ortaya konmuştur. Zaman içinde yasalara tüm deneysel gözlemleri bir anlamda özetleyen ve yeni ilişkilerin de kolayca kavranmasına izin veren özlü bir matematiksel biçim verilmiştir. Çalışmada Maxwell'in yeri, kronolojik olarak bu kısımdır. Bahsi geçen fiziksel model, elektromanyetik olayları daha temel, daha az karmaşık olduğuna inanılan klasik mekanik aracılığıyla anlama çabasında kullanılmak için oluşturulmuştur. Ancak sonraki gelişmeler, yeni oluşturulan kavramsal yapının klasik mekanikten farklı olduğunu göstermiştir. ${ }^{47}$ Sonrasında elektromanyetizmanın mekanik modelleri terk edilmiş ve elektromanyetik kuram, fiziğin temelde ayrı bir dalı olarak kabul görmüştür. ${ }^{48}$

Maxwell'in başarısı temelde kuramsal olsa da daha sonra yol açtığı uygulamalı gelişmeler, kuramın bilim tarihinde taşıdığı önemin bir göstergesi olarak yorumlanabilir. Şu an biliyoruz ki doğada dört adet temel kuvvet bulunmaktadır. Bunlar: yerçekimi kuvveti, elektromanyetizma kuvveti, zayıf çekirdek kuvvetleri ve güçlü çekirdek kuvvetleridir. Maxwell'in buradaki katkısı, elektrik ve manyetizmayı ayrı ayrı değil de bir tek kuvvet alanı haline getirerek matematiksel bir yapıya dönüştürmesidir. Ayrıca ışık hızının mutlak bir sabit olarak kullanılabileceği fikri, sonrasında Einstein'ın görelilik denklemlerine de dayanak olmuştur. Einstein'ın görelilik kuramında bile göreli kılınamayan bu olgu, modern fiziğin bütününde en önemli buluşlardan biri olma değerini taşımaktadır. Dolayısıyla modern fiziğin ortaya çıkışı ve ilerlemesindeki kilit isimlerden birinin Maxwell olduğunu söyleyebilmekteyiz. Einstein ve Maxwell'in devrimsel buluşlarındaki ortak özellik, onların denklem veya argümanlardaki bir tek yapı veya simetriyi sezinlemeleridir.

Maxwell'in çalışmasının dikkat çeken bir başka özelliği de matematiğin fizikteki önemi üzerinedir. Kendisi de kuramsal keşfinin özellikle başlangıç sürecinde bu duruma dikkat çekmiştir. Metinde de ele alındığı gibi Maxwell, elektrik ve manyetizma üzerine yapılan çalışmaları incelerken matematikçi ve fizikçi kıyası yapmıştır. Bu kıyası sonucunda, matematikçiler tarafından keşfedilmiş en verimli araştırma yöntemlerinin bazılarının özgün biçimlerinde olmak yerine, Faraday tarafından elde edilen fikirler cinsinden çok daha iyi ifade edilebildiklerini bulmuştur. Bu örnekten de anlaşılacağı üzere bilim tarihi, fizik evren algımızdaki devrim niteliği taşıyan gelişmelerin, empirik gözlemlerle salt matematiksel sezginin bir arada kullanılması sayesinde ortaya çıktığını göstermiştir. Maxwell'in de işaret ettiği gibi fizik adına matematik, yalnızca hesaplamaların yapılabilmesi için kullanılan bir araç değildir. Matematik, kavramsal yapıların bütünlüğünü oluşturmada da bir kaynaktır. Bu durum, fizik dünyanın doğasını anlamada matematiğin vazgeçilemez bir unsur olduğunun göstergesidir.

Finansal Destek: Yazar bu çalışma için finansal destek almamıştır.

47 Sir Edmund Whittaker, From Euclid to Eddington (New York: Dover Publications, Inc, 1958), 204.

48 Cushing, Fizikte Felsefi Kavramlar, 28. 


\section{Kaynaklar}

Cushing, James T. Fizikte Felsefi Kavramlar. Çeviren Özgür Sarıŏlu. İstanbul: Sabancı Üni. Yayınları, 2006. Dereli, T. ve Verçin A. Kuantum Mekaniği. Ankara: Türkiye Bilimler Akademisi, 2014.

Einstein, Albert. Bilim ve Felsefe Yazıları. Çeviren Nejat Bozkurt. Ankara: Sentez Yayıncılık, 2013.

Einstein, A. ve Infeld, L. Fiziğin Evrimi. Çeviren S. Turgal. Ankara: Alter Yayıncllk, 2015.

Gribbin, John. Bilim Tarihi. Çeviren Barış Gönülşen. İstanbul: Alfa Yayıncılık, 2013.

Guillen, Michael. Dünyayı Değiştiren Beş Denklem. Çeviren Gürsel Tanrı̈ver. Ankara: Tübitak Yayınları, 2002.

Heisenberg, Werner. Çağdaş Fizikte Doğa. Çeviren Vedat Günyol ve Orhan Duru. Ankara: V Yayınları, 1987. İdemen, Mithat. Elektromanyetik Alan Teorisinin Temelleri. İstanbul: İTÜ Vakfi Yayınları, 2015.

Jackson, John D. Classical Electrodynamics. New York: John Wiley \& Sons, Inc., 1962.

Ladyman, James. Understanding Philosophy of Science. London and New York: Routledge, 2002.

Maxwell, James Clerk. Treatise on Electricity and Magnetism. London: Macmilan and Co .,1873.

Pais, Abraham. Subtle is the Lord. Hampshire: Oxford University Press, 2005.

Reitz, John R. ve Milford, Frederick J. Foundations of Electromagnetic Theory. London: Addison-Wesley Publishing Company, Inc, 1992.

Whittaker, Sir Edmund. From Euclid to Eddington. New York: Dover Publications, Inc, 1958. 